\title{
COMPARATIVE STUDY OF LAPAROSCOPIC AND OPEN REPAIR OF DUODENAL ULCER PERFORATION
}

\author{
Khaled A. Elfekky, Mohamed M. Omar, Mohamed I. Hassan, and \\ Assem M. Abo Yousef
}

Department of General Surgery
Faculty of Medicine -Ain
Shams University, Cairo -
Egypt
Corresponds:
Assem M. Abo Yousef
E.male:
dr_assem_yousef@yahoo.com
Tel.: 01002351056
Received: 7/3/2019
Accepted: 3/4/2019

\section{ABSTRACT:}

Background: Duodenal ulcer perforation is one of the common complications of duodenal ulcer disease despite the use of various anti-ulcer agents and eradication therapy. Laparoscopy has become increasingly popular in management of duodenal ulcer perforation.

Aim of the Work: to compare between the efficacy and safety of laparoscopic and laparotomy repair of perforated duodenal ulcer in terms of operative time, postoperative pain, postoperative complication, Hospital stay and resuming normal activity.

Patient and Methods, This prospective study included 50 patients with perforated duodenal peptic ulcer were admitted to the General Surgery Department in Ain Shams University Hospitals and Ahmed Maher Teaching Hospital from May 2016 to December 2017. The patients were divided by random serial number method into two groups: group A included 25 patients for laparoscopic procedure, and group B included 25 patients for open repair.

Results: laparoscopic repair of perforated peptic ulcers is superior to the open repair as regards the postoperative pain, return of bowel habit, start of oral diet and length of hospitalization. Currently, the main drawbacks of laparoscopic repair are a longer operation and a higher incidence of intra-abdominal collection. The open repair has a higher rate of chest infection, wound infection. Suture leakage was reported in one case in the open group and in one case in laparoscopic group.

Conclusion: laparoscopic repair of perforated peptic ulcers is a safe emergency procedure with many advantages such as less postoperative pain, early return of bowel habit, early start of oral diet, less length of hospitalization, good cosmetic outcome and less postoperative complications as(wound infections, chest infections and incisional hernias).

Key words: Laparoscopic, Open Repair, Duodenal Ulcer Perforation

\section{INTRODUCTION:}

Every year duodenal ulcer disease affects 4 million people around the world. Complications are encountered in 10\%-20\% of these patients and $2 \%-14 \%$ of the ulcers will perforate. Perforated duodenal ulcer is relatively rare, but life-threatening with the mortality varying from $10 \%$ to $40 \%$. More than half of the cases are female and they are usually older and have more co-morbidities than their male counterparts ${ }^{(\mathbf{1})}$.

Main etiologic factors include use of (NSAIDs); type A personalities, steroids, smoking, Helicobacter pylori and a diet high 
Khaled A. Elfekky, et al.,

in salt. All these factors have in common that they affect acid secretion in the gastric mucosa. Defining the exact etiological factor in any given patient may often be difficult, as more than one risk factor may be present and they tend to interact ${ }^{(2,3)}$.

Duodenal ulcer perforation is one of the common complications of duodenal ulcer disease despite the use of various anti-ulcer agents and eradication therapy. It is one of the most common causes of admission in casualty worldwide and particularly more in developing nations ${ }^{(4)}$.

Common sites for peptic ulcers are the first part of duodenum and the lesser curvature of the stomach, they may Also occur on the stoma after gastric surgery, esophagus and even In Meckel's diverticulum. Duodenal ulcer perforation is an abdominal emergency, and is in third in frequency, after acute appendicitis and acute intestinal obstruction ${ }^{(5)}$.

The conventional open technique deal well with the perforation and peritoneal lavage but has the disadvantages of large upper abdominal incision, wound infection, wound dehiscence, prolonged ileus and pulmonary complications and late complications of incisional hernias. Perforated duodenal ulcer is a condition in which laparoscopic repair is an attractive option. Not only it is possible to identify site and pathology of the perforation, but the procedure also allows closure of the perforation and peritoneal lavage, just like in open repair but without a large upper abdominal incision. But the effects of laparoscopy in the setting of generalized peritonitis, physiological disturbances which are unpredictable need to be balanced with the advantages of faster recovery ${ }^{(6)}$.
Since the late 1980s, laparoscopy has become increasingly popular. In the beginning, laparoscopy was mainly used for elective surgery, as the influence of the pneumoperitoneum on the acute abdomen with peritonitis was not clear. However, the benefits of laparoscopy with regard to the acute abdomen as a diagnostic tool have been established, and since then its therapeutic possibilities also seem to be advantageous. Laparoscopic repair confers benefits including reduced postoperative pain, less pulmonary infection, shorter hospital stay, and earlier return to normal $\operatorname{activities}^{(7)}$.

\section{AIM OF THE WORK:}

The aim of this study is an effort to compare between the efficacy and safety of laparoscopic and laparotomy repair of perforated duodenal ulcer in terms of operative time, postoperative pain, postoperative complication, Hospital stay and resuming normal activity.

\section{PATIENT AND METHODS:}

This is a prospective study that included 50 patients with perforated duodenal peptic ulcer were admitted to the General Surgery Department in Ain Shams University Hospitals and Ahmed Maher Teaching Hospital from May 2016 to December 2017. The patients will be divided by random serial number method into two groups: group A included 25 patients for laparoscopic procedure, and group B included 25 patients for open repair

\section{Data collection:}

Data was collected from patients' records, medical files and interviews. 


\section{Inclusion Criteria:}

Patients with clinical and radiological diagnosis of perforated duodenal Ulcer only between 15 and 70 years without sex discrimination with stable hemodynamics and Boey's score $(0,1)$ were included in the study.

\section{Exclusion Criteria:}

1. Hemodynamics instability

2. Complicated ulcers like bleeding ulcer, ulcer situated over posterior wall

3. Clinically sealed perforation

4. Patients with abdominal malignancy

5. Patients with COPD, heart disease, coagulopathy obesity, cirrhosis, advanced pregnancy

6. Boey's score $(2,3)$

Conversion criteria for laparoscopy to laparotomy

1. Technical difficulties

2. Concomitant haemorrhage

3. Hemodynamic instability during Laparoscopic repair
4. Perforated duodenal ulcer $>1 \mathrm{~cm}$

- Surgical technique for laparoscopy procedure

At the beginning of the procedure, the patient was placed in the supine position with the legs straight and spread out. The patient's position was changed in the antiTrendelenburg position during suture and in the Trendelenburg position during peritoneal lavage.

The surgeon stands between the patient's legs and the assistant to the patient's left. This position changed during peritoneal lavage with the surgeon to the left of the patient and assistant between the patient's legs. The laparoscopic unit was placed on the patient's left side toward the shoulder. The instrument table is placed at the patient's legs.

The Veress needle or an open technique was used to enter the abdomen. Intraabdominal pressure between 8 and 12 $\mathrm{mmHg}$ was usually sufficient to realize enough room to work properly.An optical trocar of $10-12 \mathrm{~mm}$ was introduced in the peri-umbilical region. (Port 1)

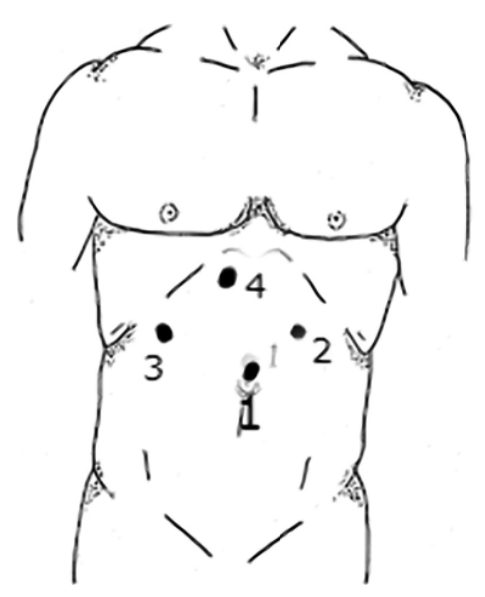

Figure (1): Port sites.

Under visual control two additional approximately in the middle between the ports were placed, a $10 \mathrm{~mm}$ port xiphoid process and umbilicus (port 2), 
slightly paramedian to the left and a $5 \mathrm{~mm}$ port in the right midclavicular line below the costal margin (port 3) and the port for liver retraction just below the xiphoid process slightly to the right (port4).

The abdomen was explored to identify the perforation and to assess the magnitude of peritonitis. Once the liver was retracted, the exposed area was carefully checked, and the perforation was usually clearly identified as a small hole on the anterior aspect of the first portion of the duodenum.

The next step was cleaning the abdomen. The whole abdomen must be irrigated and aspirated with warm salinesolution; about 4-6 L of warm saline was necessary to clean the abdomen. For direct closure of the perforation by interrupted 2/0 Vicryl absorbable sutures, usually three stitches are placed in a transversal manner over the perforation focused on the pyloroduodenal axis. A big bite of $0.5-1 \mathrm{~cm}$ from the perforation edge required to avoid cutting through of the friable ulcer edges. The knot is tied using the intracorporeal knotting. We avoided the extracorporeal stitches as the edges of the perforation were friable and cannot withstand any traction.

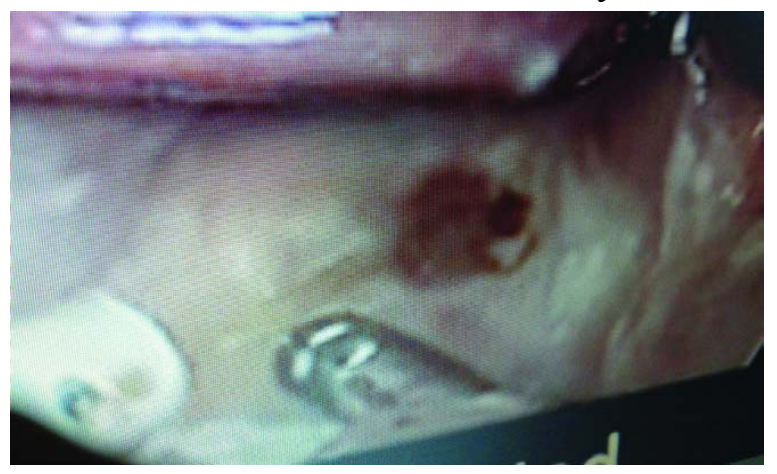

Figure (2): The site of the perforation.

Once the perforation is closed, a small fragment of the greater omentum can be fixed over the suture line. When it is difficult to approximate the edges of the ulcer, as is the case with chronic callous ulcers and large perforation, direct closure of perforation should be avoided and closure of the perforation with an omental patch only, as in the open technique, must be used to avoid cutting the duodenal wall.

Before ending the operation, routine drainage of the peritoneal cavity was performed, and the abdomen must be examined for any possible bowel injury or hemorrhage.

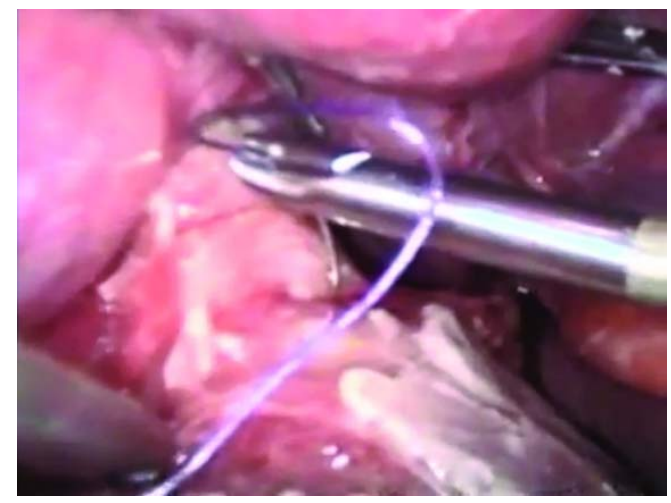

Figure (3): Intracorporeal stitching of the perforation. 


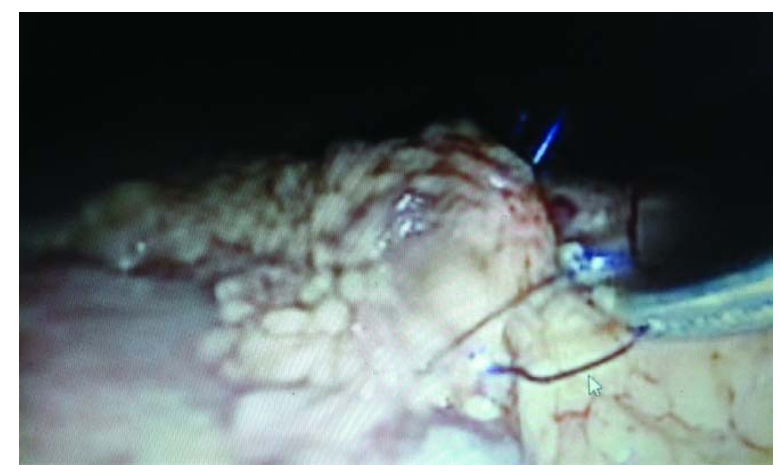

Figure (4): Omental patch over the sutured perforation.

\section{- Surgical technique for open procedure}

The patient was placed in the supine position and general anesthesia was administered. An exploratory upper midline incision was done. After formal exploration and identification of perforation, we used the Graham patch technique in which three interrupted sutures used. A piece of omentum was lying over these sutures, which tied just sufficiently tight to hold the omental graft in situ.Peritoneal toilet with warm saline until become clear, drains inserted and closure of abdomen

\section{Post-operative:}

1. The patients received a proton pump inhibitor intravenously in the hospital

2. Intravenous antibiotic therapy maintainned depending on the severity of the peritonitis.

3. The nasogastric tube removed once the peristalsis resumed and the intestinal sounds were audible.

4. Food intake restored on the third day post-operative and the drain removed once the effluent is less than $100 \mathrm{ml}$ per day and serous in nature.

5. Anticoagulant with enoxaparin administered mainly to the obese patients BMI more than 40 during the entire postoperative hospital stay prophylaxis against DVT and PE.
6. Triple therapy for Helicobacter pylori should be administered to all patients and after6 weeks postoperatively

\section{Outcome measures:}

1. Operative time

2. Score of pain

3. Post-operative complication

4. Incidence of reoperation owing to leakage at the repair site

5. Hospital stay

6. Resuming to normal activity

\section{Follow-up:}

Patients with a history of chronic ulcer, using of NSAIDs and infection with $\mathrm{H}$. pylori was more likely to have persistent signs, symptoms, and complications of duodenal ulcer. Therefore, the postoperative follow-up of patients with perforated duodenal ulcers was including the following: combination of antibacterial and antisecretory therapy to eradicate $H$. pylori should be administered to all patients and after6 weeks postoperatively.

\section{RESULTS:}

I. Preoperative results :

\section{A-Demographic data :}

\section{1- Gender distribtion :}

Patients were divided according to gender in each group. Most of the patients were males. 
Khaled A. Elfekky, et al.,
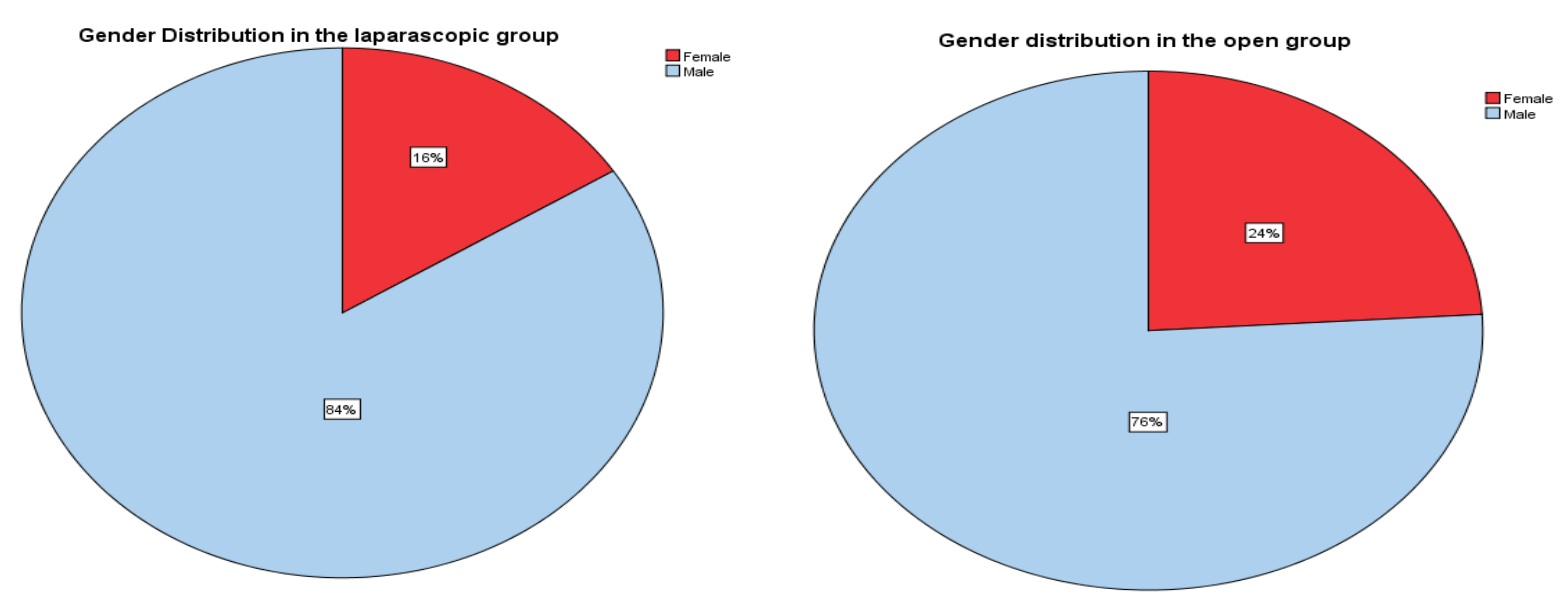

Diagram: Distribution of patients according to gender.

\section{2- Age distribution:}

Patient's age ranged from 15-70 years with a mean age of 42 years in laparoscopic group and 44 years in open group. The patients in each group were further divided into 5 age groups; the second age group (3040 years) represented the largest age cluster in the two study groups as shown in Table (1).

\section{B. Patients history:}

\section{1- History of peptic ulcer disease:}

There was no history of peptic ulcer disease in more than half of patients in both groups

Table (1): History of peptic ulcer disease

\begin{tabular}{|l|l|l|l|l|l|l|}
\hline $\begin{array}{l}\text { History of peptic ulcer } \\
\text { disease }\end{array}$ & Group & Total & $X^{2}$ & $\mathrm{P}^{*}$ \\
\cline { 2 - 4 } No & Count (\%) & Lap(25) & Open(25) & & \\
\hline Yes & Count (\%) & $15(60 \%)$ & $14(56 \%)$ & $29(58 \%)$ & 0 & 1 \\
\hline
\end{tabular}

- Percentage of the respective group

* P value was calculated using Chi square of independence

\section{2-History of NSAIDs intake in both groups}

NSAIDs intake was not common in both groups as shown in Table (2).

Table (2): Incidence of NSAID intake in both groups

\begin{tabular}{|c|c|c|c|c|c|c|}
\hline \multicolumn{7}{|c|}{ Crosstab } \\
\hline \multirow{2}{*}{\multicolumn{2}{|c|}{ NSAID }} & \multicolumn{2}{|l|}{ Group } & \multirow[t]{2}{*}{ Total } & \multirow[t]{2}{*}{$\mathrm{X}^{2}$} & \multirow[t]{2}{*}{$\mathrm{P}^{*}$} \\
\hline & & Lap(25) & Open(25) & & & \\
\hline No & Count $(\%)^{*}$ & $17(68 \%)$ & $19(76 \%)$ & $36(72 \%)$ & \multirow[t]{2}{*}{0.46} & \multirow[t]{2}{*}{0.49} \\
\hline Yes & Count $(\%)^{\circ}$ & $8(32 \%)$ & $6(24 \%)$ & $14(28 \%)$ & & \\
\hline
\end{tabular}

$\mathrm{X}^{2}$ chi square

- Percentage of the respective group

* P value was calculated using Chi square of independence .

\section{3- History of smoking:}

Most of the patients in both groups were smokers as shown in Table (3) 


\section{Comparative study of laparoscopic and open repair of duodenal ulcer perforation}

Table (3): Prevalence of smoking in both groups

\begin{tabular}{|c|c|c|c|c|c|c|}
\hline \multicolumn{7}{|c|}{ Cross tab } \\
\hline \multirow{2}{*}{\multicolumn{2}{|c|}{ Smoking }} & \multicolumn{2}{|c|}{ Group } & \multirow[t]{2}{*}{ Total } & \multirow[t]{2}{*}{$\mathrm{X}^{2}$} & \multirow[t]{2}{*}{$\mathrm{P} *$} \\
\hline & & $\operatorname{Lap}(25)$ & Open(25) & & & \\
\hline No & Count $(\%)^{\circ}$ & $8(32 \%)$ & $9(36 \%)$ & $17(34 \%)$ & \multirow[t]{2}{*}{0.14} & \multirow[t]{2}{*}{0.71} \\
\hline Yes & Count $(\%)^{\circ}$ & $17(68 \%)$ & $16(64 \%)$ & $30(66 \%)$ & & \\
\hline
\end{tabular}

$\mathrm{X}^{2}$ chi square

- Percentage of the respective group

* P value was calculated using Chi square of independence

\section{Clinical presentation:}

The most common presenting symptoms were sudden onset of severe epigastric pain in $(100 \%)$, abdominal distention in $(72 \%)$ and vomiting in $(50 \%)$ patients. Abdominal tenderness and classical signs of peritonitis were demonstrable in $(92 \%)$ and $(80 \%)$ patients respectively as shown in Table (4).

Table (4): Clinical presentation in both groups

\begin{tabular}{|l|c|c|c|c|c|c|}
\hline \multirow{2}{*}{ Clincal presentation } & \multicolumn{2}{|c|}{$\begin{array}{c}\text { Lap } \\
(25)\end{array}$} & \multicolumn{2}{c|}{$\begin{array}{c}\text { Open } \\
(25)\end{array}$} & $\mathrm{X}^{2}$ \\
\cline { 2 - 7 } & $\mathrm{N}$ & $(\%)^{*}$ & $\mathrm{~N}$ & $(\%)^{*}$ & & \\
\hline Severe abdominal pain & 25 & 100 & 25 & 100 & 1.28 & 0.25 \\
\hline Abdominal distention & 16 & 64 & 18 & 72 & 1.83 & 0.17 \\
\hline Vomiting of & 9 & 50 & 9 & 50 & 0.0 & 1.1 \\
\hline Abdominal tenderness & 20 & 80 & 23 & 92 & 3.4 & 0.055 \\
\hline $\begin{array}{l}\text { Classical signs } \\
\text { peritonitis }\end{array}$ & 72 & 20 & 80 & 0.21 & 0.64 \\
\hline
\end{tabular}

$\mathrm{X}^{2}$ chi square

- percentage of the respective group

* P value was calculated using Chi square of independence

\section{II. operative results:}

\section{A-Operative time:}

The mean operative time was significantly longer in the laparoscopic group than the open one. Table (5)

Table (5): Comparison between operative times in minutes in both groups

\begin{tabular}{|c|c|c|c|c|c|}
\hline & Group & $\mathrm{N}$ & Mean \pm SD & $\mathrm{t}$ & P* \\
\hline Operation Time (minutes) & Lap & 25 & $141 \pm 10$ & \multirow{2}{*}{4.3} & $<0.001$ \\
\cline { 2 - 4 } & Open & 25 & $106 \pm 12$ & & \\
\hline
\end{tabular}

\section{B-Conversion to open surgery:}

Three patients of the laparoscopic group were converted to open repair with a conversion rate $12 \%$.

\section{Postoperative results :}

\section{A-Postoperative pain:}

The post-operative pain was significantly higher in the open group than the laparoscopic one. Table (6) 
Khaled A. Elfekky, et al.,

Table (6): Estimation of the postoperative pain using the Numerical pain scale scoring system (0-10) in both groups

\begin{tabular}{|l|l|l|c|c|c|}
\hline & Group & $\mathrm{N}$ & Mean \pm SD & $\mathrm{t}$ & $\mathrm{P}^{*}$ \\
\hline \multirow{2}{*}{ Post operation pain } & Lab & 25 & $2 \pm 1$ & \multirow{2}{*}{-3.846} & \multirow{2}{*}{0.001} \\
\cline { 2 - 4 } & Open & 25 & $6 \pm 1$ & & \\
\hline
\end{tabular}

* P value was calculated using unpaired sample t-test

\section{B-Return of bowel habit:}

Bowel habits return more early in the laparoscopic group than the open one. Table (7) Table (7): Return of bowel habits after surgery in both groups (per days)

\begin{tabular}{|l|l|l|l|l|l|}
\hline & Group & $\mathrm{N}$ & Mean \pm SD & T & P* \\
\hline \multirow{2}{*}{ Return of bowel habit (days) } & Lap & 25 & $1.3 \pm 0.9$ & 2.912 & \multirow{2}{*}{0.021} \\
\cline { 2 - 4 } & Open & 25 & $2.5 \pm 0.5$ & & \\
\hline
\end{tabular}

* P value was calculated using unpaired sample t-test

\section{C-Oral diet intake:}

Start of oral diet intake was significantly earlier in the laparoscopic group than the open one. Table (8)

Table (8): Time of the start of oral intake (in days) after surgery among the two groups:

\begin{tabular}{|l|l|l|l|l|l|}
\hline & Group & $\mathrm{N}$ & Mean \pm SD & t & P* \\
\hline $\begin{array}{l}\text { Start } \\
\text { (days) }\end{array}$ & Lab & 25 & $2.5 \pm 0.5$ & -3.913 & $<0.001$ \\
\cline { 2 - 5 } & Open & 25 & $3.7 \pm 1$ & & \\
\hline
\end{tabular}

* P value was calculated using unpaired sample t-test

\section{D-Nasogastric tube removal:}

Nasogastric $(N / G)$ tuberemoval was significantly earlier in the laparoscopic group than the open one

Table (9): Time of N/G tuberemoval (in days) after surgery among the two groups

\begin{tabular}{|l|l|l|c|c|c|}
\hline & group & $\mathrm{N}$ & Mean $\pm \mathrm{SD}$ & $\mathrm{t}$ & $\mathrm{P}^{*}$ \\
\hline \multirow{2}{*}{$N / G$ tube removal (days) } & Lab & 25 & $1.4 \pm 0.5$ & \multirow{2}{*}{-3.487} & 0.001 \\
\cline { 2 - 4 } & Open & 25 & $2.7 \pm 0.9$ & & \\
\hline
\end{tabular}

* P value was calculated using unpaired sample t-test

\section{E-Length of hospital stay:}

Table (10)

Hospital stay was significantly longer in the open group than the laparoscopic one.

Table (10): Length of postoperative hospital stay (in days) among the two groups.

\begin{tabular}{|l|l|l|l|l|l|}
\hline & group & $\mathrm{N}$ & Mean \pm SD & t & P* \\
\hline \multirow{2}{*}{ Hospital stay (days) } & Lab & 25 & $4.4 \pm 0.8$ & -2.687 & \multirow{2}{*}{0.011} \\
\cline { 2 - 4 } & Open & 25 & $6.2 \pm 0.8$ & & \\
\hline
\end{tabular}

* P value was calculated using unpaired sample t-test

\section{G-Incidence of wound complications:}

Wound complications in the form of surgical site infection (two cases), wound seroma (three cases) and wound dehiscence (one case) occurred only in the open group. 


\section{Comparative study of laparoscopic and open repair of duodenal ulcer perforation}

The incidence of wound complications was more common in the open group as shown in Table (11).

Table (11): Incidence of wound complications among both groups

\begin{tabular}{|c|c|c|c|c|c|c|}
\hline & \multicolumn{2}{|c|}{ Group } & \multirow[t]{2}{*}{ Total } & \multirow[t]{2}{*}{$\mathrm{X}^{2}$} & \multirow[t]{2}{*}{$\mathrm{P}^{*}$} \\
\hline \multicolumn{2}{|c|}{ Wound infection } & $\operatorname{Lap}(25)$ & $\operatorname{Open}(25)$ & & & \\
\hline No & Count (\%) & $25(100 \%)$ & $21(84 \%)$ & $46(92 \%)$ & 7.2 & $0.007^{*}$ \\
\hline Yes & Count (\%) & 0 & $4(16 \%)$ & $4(8 \%)$ & & \\
\hline
\end{tabular}

- percentage of the respective group

* P value was calculated using Chi square of independence

\section{H-Incidence of chest infection:}

Chest infection was higher after open surgery than laparoscopic surgery, statistically significant result. Table (12).

Table (12): Incidence of chest infection among both groups

\begin{tabular}{|l|c|c|c|c|c|c|}
\hline \multicolumn{2}{|c|}{ Chest infection } & \multicolumn{2}{|c|}{ Total } & $X^{2}$ & \multirow{2}{*}{$\mathrm{P}^{*}$} \\
\cline { 3 - 4 } & Lap(25) & Open(25) & & \\
\hline No & Count (\%) & $23(92 \%)$ & $20(80 \%)$ & $43(86 \%)$ & 4.43 & 0.035 \\
\hline Yes & Count (\%) & $2(8 \%)$ & $5(20 \%)$ & $7(14 \%)$ & & \\
\hline
\end{tabular}

- percentage of the respective group

* P value was calculated using Chi square of independence

\section{I-Incidence of suture leakage:}

There are two cases of Suture leakage that were diagnosed by gastrographin meal.

One patient in the open group developed suture leakage which was managed by surgery (omental patch repair) after failure of conservative treatment in this patient.

Also one patient developed suture leakage was reported in the laparoscopic group which managed conservatively as shown in Table (13).

Table (13): Incidence of suture leakage among both groups

\begin{tabular}{|c|c|c|c|c|c|c|}
\hline \multicolumn{2}{|c|}{ Suture leakage } & \multicolumn{2}{|c|}{ Group } & \multirow[t]{2}{*}{ Total } & \multirow[t]{2}{*}{$\mathrm{X}^{2}$} & \multirow[t]{2}{*}{$P$} \\
\hline & & Lap & Open & & & \\
\hline No & Count (\%) & $24(96 \%)$ & $24(96 \%)$ & $48(96 \%)$ & \multirow[t]{2}{*}{0} & \multirow[t]{2}{*}{1.00} \\
\hline Yes & Count (\%) & $1(4 \%)$ & $1(4 \%)$ & $2(4 \%)$ & & \\
\hline
\end{tabular}

- percentage of the respective group

* P value was calculated using Chi square of independence

\section{J-Post-operative intra-abdominal collection: \\ Post-operative intra-abdominal} collection occurred only in one patient of the laparoscopic group. The patient was diagnosed by ultra-sonography and C.T scan. The patient was managed conservatively by U/S guided aspiration and improved. 
Khaled A. Elfekky, et al.,

Table (14): Incidence ofpost-operative intra-abdominal collection

\begin{tabular}{|c|c|c|c|c|c|c|}
\hline \multirow{2}{*}{\multicolumn{2}{|c|}{ Intra abdomen collection }} & \multicolumn{2}{|l|}{ Group } & \multirow[t]{2}{*}{ Total } & \multirow[t]{2}{*}{$\mathrm{X}^{2}$} & \multirow[t]{2}{*}{$\mathrm{P}^{*}$} \\
\hline & & Lap(25) & Open(25) & & & \\
\hline $\mathrm{NO}$ & Count (\%) & $24(96 \%)$ & $25(100 \%)$ & $49(98 \%)$ & \multirow[t]{2}{*}{1.02} & \multirow[t]{2}{*}{0.31} \\
\hline Yes & Count $(\%)^{*}$ & $1(4 \%)$ & 0 & $1(2 \%)$ & & \\
\hline
\end{tabular}

IV.Follow up in out-patient clinic:

\section{A- Incicional hernia:}

By follow up in out-patient clinic, we found that two patients presented by incisional hernia in open group, while no one in laparoscopic group had this complication as shown in table (15).

Table (15): Incidence of incisional hernia among both groups

\begin{tabular}{|l|l|l|l|l|l|}
\hline Incisional hernia & Lap $(25)$ & Open(18) & $\mathrm{X}^{2}$ & $\mathrm{P}^{*}$ \\
\hline YES & Count $(\%)^{*}$ & 0 & $2(8 \%)$ & 3.27 & 0.07 \\
\hline NO & Count $(\%)^{*}$ & $25(100.0 \%)$ & $23(92 \%)$ & & \\
\hline
\end{tabular}

- percentage of the respective group

* P value was calculated using Chi square of independence

\section{DISCUSSION:}

Perforated peptic ulcer is a condition in which laparoscopic repair is an attractive option. Not only is it possible to identify the site and pathology of the perforation, but also the procedure allows closure of the perforation and peritoneal lavage, like in open repair but without a large upper abdominal incision ${ }^{(8)}$.

This prospective randomized study was conducted in Ain Shams university emergency department and Ahmed Maher Teaching Hospital included 50 patients with perforated peptic ulcers. Patients were divided into two groups; open group and laparoscopic group according to the approach that was used to manage their.

Most of the patients in this study were males $(84 \%)$, in the middle age group from 30 to 40 years old (Mean age: 42.4 years). These results were near similar to other study by Bertleff and Lange ${ }^{(2)}$ colleagues in 2010 found that most patients were male $(79 \%)$ and mean age (48) years old, also study by Sreeramulu et al. ${ }^{(3)}$ and his colleagues in 2013 found that most patients were male $(80 \%)$,but most patients were in age group from 41to 60 years old.

In this study, history of peptic ulcer disease in patients in laparoscopic group (40\%), while in open group (44\%). History of NSAID intake in laparoscopic group (44.4\%), while in open group (33.3\%), also history of smoking in laparoscopic group (77.8\%), while in open group (72.2\%), there were no significant difference in both groups in these variables.

In 2009 Karimian and his colleagues ${ }^{(9)}$ found in their retrospective study that history of peptic ulcer disease in laparoscopic group $(25.9 \%)$, while in open group $(11.1 \%)$,also history of NSAID intake in laparoscopic 
group (32\%), while in open group (24\%), also history of smoking in laparoscopic group $(68 \%)$ and in open group (64\%), there were no significant difference in both groups in these variables.

In this study, the commonest presenting symptoms were sudden onset of severe epigastric pain in (100\%), abdominal distention in $(68 \%)$ and vomiting in $(50 \%)$ patients. Abdominal tenderness and classical signs of peritonitis were demonstrable in $(86 \%)$ and $(76 \%)$ patients respectively. While in study by Chalya and his colleagues ${ }^{(\mathbf{1 0})}$ in 2011, found that the commonest presenting symptoms were sudden onset of severe epigastric pain in (97.6\%), abdominal distention in $(76.2 \%)$ and vomiting in (36.9\%) patients. Abdominal tenderness and classical signs of peritonitis were demonstrable in (88.1\%) and (66.7\%) patients respectively.

In this study, we found that three patients of the laparoscopic group were converted to open surgery, with a conversion rate $12 \%$. The reasons of conversion were large size of the perforation in one patient (more than 2 $\mathrm{cm}$ ) and difficulty in placing the sutures through the friable edges in the other two patients. In 2013, Sreeramulu and his coworkers $^{(3)}$ reported near similar conversion rate $(9.6 \%)$ in a non-randomized prospective study on 61patients, this due to large perforation (more than 2c.m.) and dense adhesion.

However, in 2010, Bertleff and his colleagues ${ }^{(11)}$ reported a lower conversion rate $(7.7 \%)$ in a prospective randomized controlled study. In a meta- analaysis conducted by $\mathrm{Lau}^{(\mathbf{1 2})}$, reported rates of conversion to open repair ranged from $0 \%$ to $29.1 \%$, with the main causes of conversion to open repair were related to difficulty identifying the site of ulcer perforation, large perforation and technical problems.
This difference in the rate of conversion to open repair between different studies is related to multiple factors, the most important are the experience of surgeons, the learning curve and good equipment.

The operative time in this study was significantly longer in the laparoscopic groups .The mean operative time was found to be $(141 \mathrm{~min})$ in the laparoscopic group compared to the open group (106 min).

The same was proved by other studies that demonstrated a significantly longer operative time for laparoscopic repair ${ }^{(3)}$.

However, study by Lauand his colleagues $^{(13)}$ showed significant difference regarding operative time between both groups.

Study by Siu and his co-workers (14) demonstrated a significantly shorter operative time for laparoscopic repair than for open repair another Study by Gyou and his colleagues $^{(15)}$ also found shorter time for laparoscopic repair than for open repair.

The variation in the operative time between different studies due to the fact that the operative teams are not equivalent in terms of experience and availability of good equipment . In our study, we found that by improving learning curve, the operative time in laparoscopic group become shorter by time.

Postoperative pain, measured using the NRS (Numerical Rating Scale), was highly significantly less in the laparoscopic group. The same was proved by other prospective studies which consistently showed a lower pain score after laparoscopic repair than after open repair ${ }^{(3)}$.

Other studies showed the same results in the form of decrease in the dosage of opiate analgesic required after laparoscopic repair than after open repair ${ }^{(\mathbf{1 4})}$. 
In the current study, the return of bowel habit was significantly early in the laparoscopic group (mean 1.33 days) compared to the open group (mean 2.53 days). Consequently, the start of oral diet was also earlier in the laparoscopic group (mean 2.57 days) than the open group (mean 3.72 days. This was reflected on the length of hospital stay which was significantly less in the laparoscopic group (mean 4.4days) compared to the open group (mean 6.2 days).

The same was shown in a prospective study reported by Bertleff and his coworker $^{(11)}$, where the start of oral diet was also earlier in the laparoscopic group (mean 3.5 days) than the open group (mean 5.72 days), a significant reduction in the hospital stay was found in the laparoscopic group (mean $=6.5$ days) versus 8days in open group.

Also some studies confirmed earlier start of oral diet and shorter hospital stay in the laparoscopic group ${ }^{(3,14,16)}$.

In this study, a higher incidence of chest infection was observed in the open group compared to the laparoscopic group with statistical significance. Also, in a randomized trial significant reduction in chest infection rate was reported for the laparoscopic group, as compared with that for the open group ${ }^{(14)}$. In contrary, Naesgaard and his co-workers ${ }^{(17)}$ demonstrated a significantly higher incidence of chest infection in the laparoscopic group.

The high incidence of chest infection in ulcer disease patients is related to the high prevalence of smoking among these groups of patients in general $(75 \%)$.

The incidence of chest infection increases more in the open group due to the higher incidence of upper abdominal pain interfering with the proper expansion of the chest.
Wound complications during hospitalization were the most common morbidity after open repair of perforated peptic ulcers with a rate of $16 \%$ compared to the laparoscopic group $0 \%$. This difference reach the statistical significance level $(p=0.007)$. The wound complications were in the form of superficial surgical site infection, wound seroma and wound dehiscence.

Four studies observed a higher incidence of wound complications in the open $\operatorname{group}^{(14,16,18,19)}$.

The difference did not reach statistical significance in first two studies, but reach statistical significance in second two studies.

However, in 2004, a meta-analysis conducted by Lau and his colleagues (13) proved a significant reduction in the wound complications in the laparoscopic group when compared to the open group in repair of perforated peptic ulcers $(p=0.036)$.

This difference in the incidence of wound complications between the two groups is a common feature to all surgical abdominal procedures; in which wound complications is higher is open surgical procedures than laparoscopic ones ${ }^{\mathbf{( 2 0 )}}$.

In this study, suture leakage occurred in two cases, one in each group (4\%) with no statistical significance. The same result was also observed in a study conducted by Ricky and his co-workers ${ }^{(21)}$.

However, in a study conducted by Bertleff his co-workers ${ }^{(11)}$, a higher incidence of leakage was found in the laparoscopic group (3\%) compared to the open group $(0 \%)$, but leakage mainly occurred in the sutureless repair group or in the group in which omentoplasty was not routinely used. However, in a study conducted by Gyou and his co-workers ${ }^{(15)}$, leakage rate reached zero $\%$. 
The incidence of suture leakage in ulcer disease patients is related to technical errors, friability of tissues and size of perforation.

In this study, we found a postoperative intra-abdominal collection was observed in one case (4\%) after laparoscopic repair.

This occurred in the first case mostly due to inadequate equipment. no case in open group. This emphasizes the importance of performing an adequate lavage especially if the laparoscopic approach is chosen. A Metaanalysis conducted by Gyou and his colleagues $^{(15)}$ demonstrated that there was no significant difference between open and laparoscopic repair regarding the incidence of postoperative intra-abdominal collection or abscess formation.

However, in study by Lau and his colleagues ${ }^{(\mathbf{1 2})}$, they found that postoperative intra-abdominal collection was observed in three cases out of 35 cases (8.5\%) after open repair, no single case in laparoscopic group.

In this study, incisional hernia was observed two cases (8\%) in open group, while no hernia developed in laparoscopic group, but in study conducted by Schmidt and his co-workers ${ }^{(22)}$ found only one case in open group $(2.2 \%)$. Incisional hernia more in open group due to long midline incision and more wound complications

One benefit of the laparoscopic procedure in this study is cosmetic outcome. Nowadays patients are aware of this benefit, and sometimes this is the reason why they ask for laparoscopic surgery. Another benefit of the laparoscopic procedure in this study less postoperative adhesions that contributed to small incisions and less manipulations

Based on the statistical analysis, we found that the laparoscopic repair of perforated peptic ulcers is superior to the open repair as regards the postoperative pain, return of bowel habit, start of oral diet and length of hospital stay. Currently, the main drawbacks of laparoscopic repair are a longer operative time and difficult repair of large sized perforation. While the main drawbacks of the open repair have a higher rate of chest infection, wound complications and less cosmetic outcome.

\section{REFERENCE:}

1. Zelickson MS, Bronder CM, Johnson BL, Camunas JA, Smith DE, Rawlinson D, Von S, Stone HH, Taylor SM: Helicobacter pylori is not the predominant etiology for peptic ulcers requiring operation. Am Surg, 77:1054-1060. PMID: 21944523. (2011)

2. Bertleff MJ, Lange JF: Perforated peptic ulcer disease: a review of history and treatment. Dig Surg 2010, 27:161-169 [PMID: 20571260 doi: 10.1159/ 000264653].

3. Sreeramulu PN, Venkatachalapathy TS, Supreet CS, Prathima S. A comparative study of laparoscopic vs open surgery for the management of duodenal ulcer perforation. World Journal of Laparoscopic Surgery. 2013 Jan;6(1):11-4.

4. Møller MH, Adamsen S, Wøjdemann M, Møller AM: Perforated peptic ulcer: how to improve outcome? Scand J Gastroenterol 2009, 44:15-22 [PMID: 18752147 doi:10. 1080/00365520802307997].

5. Thorsen K, Glomsaker TB, von Meer A, Søreide K, Søreide JA: Trends in diagnosis and surgical management of patients with perforated peptic ulcer. J Gastrointest Surg, 15:1329-1335 [PMID: 21567292 doi: 10.1007/ s11605-011-1482-1].(2011)

6. Mahvi D, Krantz S. Peptic ulcer disease. In: Townsend C, Beauchamp R, ed. By. Sabiston Textbook of Surgery. 19th ed. Elsvier Saunders; 2012. p. 1193-1200.

7. Lo HC, Wu SC, Huang HC. Laparoscopic simple closure alone is adequate for low risk patients with perforated peptic ulcer. World J Surg2011; 35:1873-1878 


\section{Khaled A. Elfekky, et al.,}

8. Thirby RC: Closure of duodenal perforations. Operative Techniques in General Surgery; Volume 5, Issue 2: 59-64. (2013)

9. Karimian F, Aminian A, Lebaschi AH, Mirsharifi R, Alibakhshi A. Perforated peptic ulcer, comparison between laparoscopic and open repair. Shiraz E Medical Journal. 2009;10(1):20-6.

10. Chalya PL, Mabula JB, Koy M, Mchembe MD, Jaka HM, Kabangila R, Chandika AB, Gilyoma JM. Clinical profile and outcome of surgical treatment of perforated peptic ulcers in Northwestern Tanzania: A tertiary hospital experience. World Journal of Emergency Surgery. 2011 Dec;6(1):31.

11. Bertleff MJ and Johan FL: Laparoscopic correction of perforated peptic ulcer: first choice? A review of literature. Surg Endosc;24(6): 1231-1239. (2010)

12. Lau H: Laparoscopic repair of perforated peptic ulcer: a meta-analysis. Surg Endosc ; 18(7):1013-1021. (2014)

13. Lau JY, Sung J, Hill C, Henderson C, Howden CW, Metz DC: Systematic review of the epidemiology of complicated peptic ulcer disease: incidence, recurrence, risk factors and mortality. Digestion 2011, 84:102-113. PMID: 21494041.

14. Siu WT, Leong HT and Law BK: Laparoscopic repair for perforated peptic ulcer: a randomized controlled trial. Ann Surg; 235: 313-319. (2012)

15. Gyou Ra Lee, Kyung park and Sung kim (2012): Laparoscopic primary closure, a better method of treatment of perforated peptic ulcer than open repair. Journal of minimally invasive surgery; 15:11-14.

16. Mehendale VG, Shenoy SN and Joshi AM (2002): Laparoscopic versus open surgical closure of perforated duodenal ulcer: a comparative study. Indian Journal of Gastroentrology; 21:222-224

17. Naesgaard JK,Edwin B and Reiertsen O (1999): Laparoscopic and open operation in patients with perforated peptic ulcer. European Journal of Surgery; 165: 209-214.

18. Katkhouda N, Mavor E and Mason RJ (1999): Laparoscopic repair of perforated duodenal ulcers: outcome and efficacy in 30 consecutive patients. Arch Surg; 134: 845850.

19. Kok KY, Mathew VY and Yapp SK (1999): Laparoscopic omental patch repair for perforated peptic ulcer. Am Surg;65(1): 27 30.

20. Fanaie SA, Ziaec SA and Goodman KJ (2007): Safety of oral feeding after repair of perforated peptic ulcer. Indian J Surgery; 67:185-188

21. Ricky HB, Ruvinder A and Damien D (2007): Comparison between open and laparoscopic repair of perforated peptic ulcer disease. World Journal Surgery; 32(11):2371-2374.

22. Schmidt HG, Marietta J and Olga B (2009): Randomized clinical trial of laparoscopic versus open repair of perforated peptic ulcer. World Journal of Surgery;33:1368-1373. 